\title{
The patient burden of screening mammography recall.
}

\author{
Matthew Alcusky \\ School of Population Health, Thomas Jefferson University \\ Liane Philpotts \\ Yale University School of Medicine \\ Machaon Bonafede \\ Truven Health Analytics \\ Janice I. Clarke \\ School of Population Health, Thomas Jefferson University \\ Alexandria Skoufalos \\ School of Population Health, Thomas Jefferson University \\ Follow this and additional works at: https://jdc.jefferson.edu/healthpolicyfaculty \\ Part of the Public Health Commons \\ Let us know how access to this document benefits you
}

\section{Recommended Citation}

Alcusky, Matthew; Philpotts, Liane; Bonafede, Machaon; Clarke, Janice I.; and Skoufalos, Alexandria, "The patient burden of screening mammography recall." (2014). College of Population Health Faculty Papers. Paper 71.

https://jdc.jefferson.edu/healthpolicyfaculty/71

This Article is brought to you for free and open access by the Jefferson Digital Commons. The Jefferson Digital Commons is a service of Thomas Jefferson University's Center for Teaching and Learning (CTL). The Commons is a showcase for Jefferson books and journals, peer-reviewed scholarly publications, unique historical collections from the University archives, and teaching tools. The Jefferson Digital Commons allows researchers and interested readers anywhere in the world to learn about and keep up to date with Jefferson scholarship. This article has been accepted for inclusion in College of Population Health Faculty Papers by an authorized administrator of the Jefferson Digital Commons. For more information, please contact: JeffersonDigitalCommons@jefferson.edu. 


\title{
The Patient Burden of Screening Mammography Recall
}

\author{
Matthew Alcusky, PharmD, MS, Liane Philpotts, MD, FSBI, ${ }^{1}$ Machaon Bonafede, $\mathrm{PhD}, \mathrm{MPH}{ }^{3}$ \\ Janice Clarke, RN, BBA, and Alexandria Skoufalos, EdD ${ }^{1}$
}

\begin{abstract}
Objective: The aim of this article is to evaluate the burden of direct and indirect costs borne by recalled patients after a false positive screening mammogram.

Methods: Women aged 40-75 years undergoing screening mammography were identified from a U.S. commercial claims database. Women were required to have 12 months pre- and 6 months post-index enrollment to identify utilization and exclude patients with subsequent cancer diagnoses. Recall was defined as the use of diagnostic mammography or breast ultrasound during 6 months post-index. Descriptive statistics were presented for recalled and non-recalled patients; differences were compared using the chi square test. Out-of-pocket costs were totaled by utilization type and in aggregate for all recall utilization.

Results: Of 1,723,139 patients with a mammography screening that were not diagnosed with breast cancer, 259,028 (15.0\%) were recalled. Significant demographic differences were observed between recalled and nonrecalled patients. The strongest drivers of patient costs were image-guided biopsy (mean $\$ 351$ among $11.8 \%$ utilizing), diagnostic mammography $(\$ 50 ; 80.1 \%)$, and ultrasound $(\$ 58 ; 65.7 \%)$, which accounted for $29.9 \%$, $29.0 \%$, and $27.5 \%$ of total recall costs, respectively. For many patients the entire cost of recall utilization was covered by the health plan. Total costs were substantially greater among patients with biopsy; one-third of all patients experienced multiple days of recall utilization.

Conclusion: After a false positive screening mammography, recalled women incurred both direct medical costs and indirect time costs. The cost burden for women with employer-based insurance was dependent upon the type of utilization and extent of health plan coverage. Additional research and technologies are needed to address the entirety of the recall burden in diverse populations of women.
\end{abstract}

\section{Introduction}

B REAST CANCER IS THE SECOND LEADING CAUSE of cancer death and the most common non-skin-related cancer in women. ${ }^{1}$ Screening mammography is used to detect presymptomatic breast cancers, providing the opportunity for earlier intervention with the goal of reducing breast cancerrelated mortality. ${ }^{2-4}$ Relative risk reductions in mortality from mammography screening have been estimated to be approximately $20 \%$ based upon the results of randomized trials involving over 650,000 women in North America and Europe. ${ }^{5-6}$ Retrospective analysis of population based United States registry data from the National Cancer Institute's Surveillance, Epidemiology, and End Results program determined that, after adjustment for underlying temporal trends, the incidence of late-stage breast cancer has decreased $37 \%$ and early-stage disease incidence has increased $48 \%$ during the mammography screening era. ${ }^{7}$ The magnitude and direction of mammography's net effect remains highly contested ${ }^{8}$ the applicability of older randomized trials must be interpreted in the context of evolving treatment paradigms and balanced with potential harms in the form of false positives, overdiagnosis, and overtreatment.

In the United States, guidelines for breast cancer screening practices are not systematically updated across societies and groups. The most recent guidelines available from the American Cancer Society and the American College of Obstetricians and Gynecologists recommend the annual screening of women at average risk beginning at age $40 .^{2,3}$ These guidelines acknowledge the importance of the individualization of screening based upon the risk profile and preferences toward benefits and harms of screening of each patient. The United States Preventive Services Taskforce (USPSTF) released updated recommendations for breast

\footnotetext{
${ }^{1}$ Jefferson School of Population Health, Philadelphia, Pennsylvania.

${ }^{2}$ Yale University School of Medicine, New Haven, Connecticut.

${ }^{3}$ Truven Health Analytics, Brentwood, New Hampshire.
} 
cancer screening in 2009 that narrowed the target population for biennial mammography screening to women between the ages of 50 and $75 .{ }^{4}$ The USPSTF asserts that despite similar benefits of screening in women ages 40-49, decreased cancer incidence and an accompanying larger number needed to screen contributes to a smaller net benefit in this population. ${ }^{4}$ Real-world data is useful to inform policy determinations, as the actual screening compliance and interval between screening mammograms varies considerably. ${ }^{9}$ Organizations within and outside of the United States have provided largely overlapping screening recommendations with certain distinctions, including triennial screening in the United Kingdom, that further emphasize the differential approach to nationally supported screening programs and interpretation of evidence surrounding mammography screening. ${ }^{10,11}$

Following a finding on a screening mammogram, the use of further diagnostic processes to investigate an inconclusive screening result (patient recall) appears to impact patients unequally. ${ }^{12,13}$ Unnecessary recall, also referred to as a false positive result, occurs when an initial screening result is followed by further diagnostic procedures and utilization that ultimately resolves with a benign outcome. The burden of unnecessary recall on the patient and health care system will vary as a function of the number, type, and associated cost of follow-up procedures required to rule out a diagnosis of breast cancer. ${ }^{13-17}$ Direct medical costs to the patient are dependent upon the presence and type of health insurance. ${ }^{18-20}$ Adverse physical or psychological effects experienced by some patients as a result of a false positive may amplify the burden. ${ }^{21-22}$ False positives have been associated with shortterm increases in anxiety ${ }^{15}$ and with temporary decrements in quality of life measures. ${ }^{22}$ Breast cancer-related anxiety may last up to 3 years after the false positive recall has been resolved. $^{23}$ Indirect costs to patients secondary to missed work time and lost productivity to employers due to presenteeism and absenteeism must also be considered. Recalled patients are required to schedule and travel to attend office visits and undergo procedures, often accompanied by a companion whose time also incurs an additional indirect cost. ${ }^{14,24}$ Additional time and travel costs for patients and their companions, and the cost of securing substitute caregivers (childcare and/or elder care, if applicable) associated with participation in a cervical cancer screening program in the United Kingdom have been estimated at $26 \%$ and $33 \%$ above direct medical costs. ${ }^{24}$

Risks associated with false positives inherent within a population-based screening approach are important considerations in the use of mammography for early detection of breast cancer. The risk of a false positive result from a screening mammogram has been estimated using nationally representative registry data from the National Cancer Institute-funded Breast Cancer Surveillance Consortium. ${ }^{12}$ The probability of a false positive was approximately $16 \%$ at an individual's first screening mammogram and $10 \%$ at subsequent screening mammograms. ${ }^{12}$ The cumulative risk of a false positive result after 10 years of screening mammograms was $61 \%$ for annual and $42 \%$ for biennial screening. ${ }^{12}$ Although the majority of false positives will prompt further imaging, the cumulative probability of biopsy after 10 years of annual or biennial mammography screens is approximately $7.8 \%$ and $4.8 \%$ respectively. ${ }^{12}$ Accumulated direct medical costs from recall-induced utilization are an- ticipated to affect total health care expenditures. One study that evaluated costs to the health plan estimated that for every $\$ 100$ spent on mammography screening and clinical breast exams an additional $\$ 33$ was spent evaluating false positive results. $^{13}$

Limited research has been conducted to evaluate the entirety of the patient burden due to recall following a false positive mammogram. In this study, we analyzed commercial claims data for a population of women with employer-based insurance to characterize patient costs associated with diagnostic pathways initiated due to unnecessary recall following an inconclusive screening mammography result.

\section{Methods}

\section{Patient selection}

The Truven Health MarketScan Commercial and Medicare Supplemental Databases were used to identify women aged 40-75 years undergoing screening mammography (index event, Current Procedural Terminology [CPT] Code G0202) from January 2011 to June 2013. Women were required to have 12 months pre- and 6 months post-index continuous enrollment, thus the study period encompassed January 1, 2010 to December 31, 2013. The Commercial and Medicare Supplemental databases contain medical claims, pharmacy claims, and enrollment data for approximately 38 million covered lives in the working population and 3 million retirees in 2012, respectively. Major data contributors include employers and health plans that cover employees and their dependents through a variety of insurance plan structures including under fee-for-service, fully capitated, and partially capitated health plans (preferred provider organizations and health maintenance organizations). The Medicare Supplemental database is representative of the national commercially insured population of those individuals who have both Medicare coverage and supplemental employer-sponsored coverage. The patient data used in this analysis was deidentified in compliance with the Health Insurance Portability and Accountability Act regulations.

The date of the first screening mammogram during the study period was designated as the index date for each patient. Women with any breast cancer screening, breast imaging procedure, or breast cancer diagnosis in the 12-month pre-index period were excluded. Similarly, women with a breast cancer diagnosis in the 6 months following the index screening mammogram were excluded from the recall analysis. Demographic characteristics (age, geographic region, health plan type) were defined on the index date.

\section{Recall definition}

Clinically, recall is determined using Breast Imaging Reporting and Data System (BI-RADS) scores to represent the percent of women recommended for additional diagnostic procedures following a screening mammogram. This analysis utilized an administrative claims database that lacks radiology reports and BI-RADS scores. Recall was defined as the utilization of imaging in the 6 months following the index screen; specifically, recall was defined as the receipt of a diagnostic mammogram (CPT codes G0204, G0206, 77055, 77056) or a breast ultrasound procedure (CPT code 76645). Other procedures that may follow imaging, such as biopsy or 
Table 1. Demographic Characteristics of Patients With and Without Unnecessary Recall Following the Index Screening Mammogram $(N=1,723,139)$ and the Recall Rate for Strata of Each Demographic

\begin{tabular}{|c|c|c|c|c|}
\hline Characteristic & $\begin{array}{l}\text { Patients with } \\
\text { recall } \mathrm{n}(\%)\end{array}$ & $\begin{array}{l}\text { Patients without } \\
\text { recall } \mathrm{n}(\%)\end{array}$ & p-value & $\begin{array}{c}\text { Recall rate by } \\
\text { demographic subgroup }\end{array}$ \\
\hline Total population screened & $259,028(100.0)$ & $1,464,111(100.0)$ & & $15.0 \%$ \\
\hline $\begin{array}{l}\text { Age (years) } \\
40-49 \\
50-64 \\
65-75\end{array}$ & $\begin{array}{c}128,299(49.5) \\
121,997(47.1) \\
8,732(3.4)\end{array}$ & $\begin{array}{c}587,429(40.1) \\
818,294(55.9) \\
58,388(4.0)\end{array}$ & $<0.001$ & $\begin{array}{l}17.9 \% \\
13.0 \% \\
13.0 \%\end{array}$ \\
\hline $\begin{array}{l}\text { Region } \\
\text { Northeast } \\
\text { West } \\
\text { South } \\
\text { Midwest } \\
\text { Mid-Atlantic } \\
\text { Other/Unknown }\end{array}$ & $\begin{array}{c}17,620(6.8) \\
40,812(15.8) \\
93,729(36.2) \\
56,568(21.8) \\
46,980(18.1) \\
3,319(1.3)\end{array}$ & $\begin{array}{c}65,594(4.5) \\
271,362(18.5) \\
549,383(37.5) \\
366,766(25.1) \\
192,028(13.1) \\
18,978(1.3)\end{array}$ & $<0.001$ & $\begin{array}{l}21.2 \% \\
13.1 \% \\
14.6 \% \\
13.4 \% \\
19.7 \% \\
14.9 \%\end{array}$ \\
\hline $\begin{array}{l}\text { Health Plan Type } \\
\text { PPO } \\
\text { HMO } \\
\text { POS } \\
\text { CDHP/HDHP } \\
\text { Comprehensive } \\
\text { EPO } \\
\text { Other/unknown }\end{array}$ & $\begin{array}{r}145,415(56.1) \\
36,226(14.0) \\
23,245(9.0) \\
22,913(8.8) \\
7,165(2.8) \\
5,479(2.1) \\
18,585(7.2)\end{array}$ & $\begin{array}{r}820,395(56.0) \\
217,092(14.8) \\
125,465(8.6) \\
128,623(8.8) \\
44,179(3.0) \\
21,151(1.4) \\
107,206(7.3)\end{array}$ & $<0.001$ & $\begin{array}{l}15.1 \% \\
14.3 \% \\
15.6 \% \\
15.1 \% \\
14.0 \% \\
20.6 \% \\
14.8 \%\end{array}$ \\
\hline $\begin{array}{l}\text { Location of Residence } \\
\text { Rural } \\
\text { Nonrural }\end{array}$ & $\begin{array}{r}33,619(13.0) \\
225,409(87.0)\end{array}$ & $\begin{array}{r}228,889(15.6) \\
1,235,222(84.4)\end{array}$ & $<0.001$ & $\begin{array}{l}12.8 \% \\
15.4 \%\end{array}$ \\
\hline
\end{tabular}

${ }^{\mathrm{a}}$ The number of patients recalled in a demographic subgroup divided by the total number of patients in that subgroup. CDHP/HDHP, consumer driven health plan/high deductible health plan; EPO, exclusive provider organization; HMO, health maintenance organization; POS, point of service; PPO, preferred provider organization.

fine needle aspiration, were not required to meet the recall definition. The number of patient-days associated with a recall was defined as the number of distinct calendar days in which a patient had a recall-related event.

Patient out-of-pocket cost was the sum of patient copayment and coinsurance costs for all breast-related diagnostic services including the following: breast-related imaging procedures in the 6 months following the index screen (e.g., diagnostic mammography, ultrasound, magnetic resonance imaging $[\mathrm{MRI}]$, ductogram, computer-aided detection), breast-related biopsy procedures and related expenses (e.g., anesthesiology and pathology), and outpatient office visits with an abnormal mammogram diagnosis code or a breastrelated diagnosis. Breast cancer treatment costs were not included in patient recall cost calculations, nor were patient insurance premiums or any costs borne by the health plan. Additional expenses realized by the patient (e.g., time off work, childcare, transportation) were not included. All costs are in 2013 US\$, adjusted using the Medical Care Component of the Consumer Price Index.

Descriptive statistics were calculated for demographic characteristics of patients with and without recall and are presented as frequencies and percentages. Differences between groups were compared using the chi-square test. Means and standard deviations were computed for costs among utilizers and among all patients for each specific type of recall utilization. Costs among patients with non-zero costs were also reported, with non-zero costs defined as occurring when the health plan did not cover all charges and the patient was responsible for a portion of the cost. Total mean and median recall costs were also reported among all recalled patients and those with non-zero cost, as well as for patients with biopsy and stratified by age cohort. Finally, the total number of distinct days with recall-associated utilization was presented as frequencies and percentages of patients to denote the indirect cost of time for patients, companions, and substitute caregivers.

\section{Results}

Of the 7,523,729 women who underwent a screening mammogram between January 1, 2010 and December 31, $2013,6,963,021$ met the age criteria. A total of $1,754,363$ women met the enrollment criteria for inclusion, of whom 31,224 patients with a breast cancer claim were excluded. The study sample comprised 1,723,139 women without a breast cancer claim during the 18-month study period, of whom $259,028(15.0 \%)$ met the definition for recall during the 6-month post-index period (Table 1).

\section{Demographics}

The majority of the women in this study were between 50 and 64 years of age $(54.6 \%)$, with the remainder of the population largely consisting of women ages 40 to 49 years $(41.5 \%)$. Recalled patients were younger than those without recall; $49.5 \%$ of recalled patients were in the youngest age cohort (40-49 years) compared with $40.1 \%(p<0.001)$ of women without recall. Approximately one-sixth $(15.2 \%)$ of 


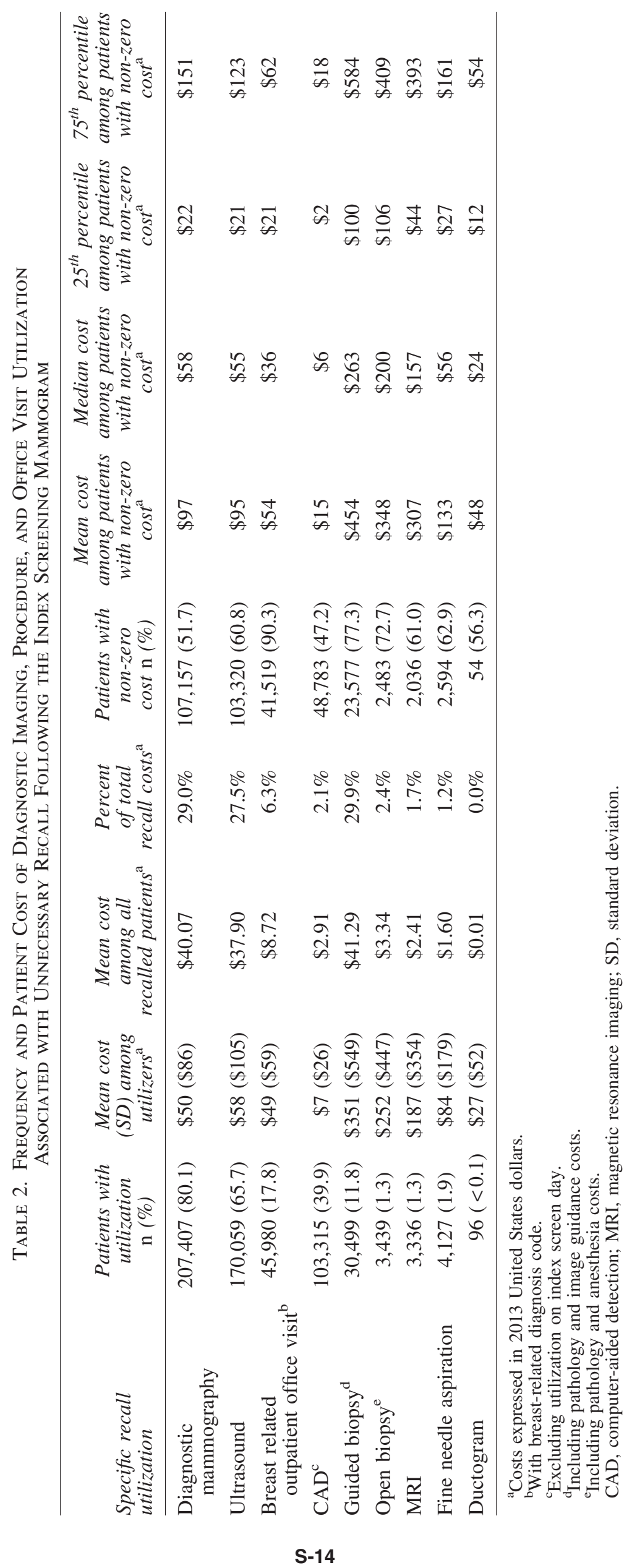


Table 3. Total Patient Costs of Diagnostic Imaging, Procedure, and Office Visit Utilization Associated with Unnecessary Recall Following the Index Screening Mammogram

\begin{tabular}{lrrrr}
\hline Statistic & Mean $(S D)^{\mathrm{a}}$ & Median $^{\mathrm{a}}$ & $\begin{array}{c}25 \text { th }^{\mathrm{a}} \\
\text { percentile }^{\mathrm{a}}\end{array}$ & $\begin{array}{c}75 \text { th }^{\text {percentile }} \\
\text { per }^{\mathrm{a}}\end{array}$ \\
\hline Average patient cost for recall $^{\mathrm{b}}$ & $\$ 137.98(\$ 303.24)$ & $\$ 33.67$ & $\$ 0.00$ & $\$ 152.81$ \\
Average cost among patients with non-zero cost $^{\mathrm{b}}$ & $\$ 206.71(\$ 351.49)$ & $\$ 95.38$ & $\$ 33.39$ & $\$ 240.81$ \\
Average cost among patients having received a biopsy $^{\mathrm{b}}$ & $\$ 448.65(\$ 636.97)$ & $\$ 223.62$ & $\$ 41.58$ & $\$ 613.45$ \\
Average patient costs for recall by age cohort $^{\mathrm{b}}$ (years) & & & & \\
$\quad$ 40-49 & $\$ 145.40(\$ 303.24)$ & $\$ 36.52$ & $\$ 0.00$ & $\$ 164.35$ \\
$50-64$ & $\$ 134.74(\$ 298.99)$ & $\$ 32.04$ & $\$ 0.00$ & $\$ 147.96$ \\
$65-75$ & $\$ 74.33(\$ 162.47)$ & $\$ 25.93$ & $\$ 0.00$ & $\$ 80.11$ \\
\hline
\end{tabular}

${ }^{\mathrm{a}}$ Costs expressed in 2013 United States dollars.

${ }^{\mathrm{b}}$ Average cost includes diagnostic imaging, procedures, and breast-related office visits associated with recall.

the screened population, and a slightly smaller percentage of the recalled patients $(13.0 \%, p<0.001)$, were identified as residing in a rural area. The geographic distribution of the screened population reflected the locations of employers and health plans constituting the Truven Health MarketScan Research databases, with the majority of the study population living in the South $(37.3 \%)$, followed by the Midwest $(24.6 \%)$ and the West $(18.1 \%)$. Differences in region of residence among patients with and without recall were significant $(p<0.001)$. Overall, the most common health plan type was preferred provider organization (56.0\%), with health maintenance organization $(14.7 \%)$ being the only other plan type covering greater than $9 \%$ of the population. Although the proportion of patients enrolled in each plan type was largely consistent, the distribution of women with and without recall among plan types was statistically significant.

The recall rate is reported for each level of demographic variables in Table 1 . The recall rate was greatest in younger women aged 40-49 years (17.9\%), compared with a consistent rate of $13 \%$ in both older age cohorts. Variability in recall rate was observed across geographic regions, with the largest recall rates in the Northeast $(21.2 \%)$ and Mid-Atlantic $(19.7 \%)$ and the lowest rates in the West $(13.1 \%)$ and Midwest $(13.4 \%)$. Patients residing in rural areas were recalled less frequently (12.8\%) compared with non-rural residents $(15.4 \%)$. Recall rates across health plan types ranged from a minimum of $14.0 \%$ for comprehensive plans to a maximum of $20.6 \%$ for exclusive provider organization (EPO) plans. With the exception of EPO plans, all plan types had a recall rate of $15.6 \%$ or less.

\section{Frequency and cost of utilization following unnecessary recall}

Diagnostic mammography was the most common type of recall-associated utilization $(80.1 \%)$, accounting for $29.0 \%$ of costs in this sample of recalled women (Table 2). Ultrasound was employed during the recall process for $65.7 \%$ of women, and computer-aided detection was used for $39.9 \%$, constituting $27.5 \%$ and $2.1 \%$ of the total patient recall cost respectively. Image-guided biopsy (\$351) and open biopsy (\$252) were the most expensive utilization types on a per procedure basis, but due to infrequent utilization open biopsy accounted for only $2.4 \%$ of total recall costs. Com- paratively, image-guided biopsy was the largest driver of total patient recall costs $(29.9 \%)$ despite use in only $11.8 \%$ of recalled patients. Ductogram $(<0.1 \%)$, fine needle aspiration $(1.9 \%)$, and MRI (1.3\%) were utilized infrequently, and these procedures together accounted for less than $3 \%$ of total recall cost.

The costs borne by patients for diagnostic imaging, procedure(s), and breast-related office visit utilization varied substantially among patients within a type of utilization as well as between different types of utilization. The variation within a utilization type is best illustrated by the marked divergence in cost burden observed when comparing patients with non-zero cost to the cost among all patients with that specific utilization type. Proportionally, this difference in cost was greatest for utilizers of diagnostic mammography for whom the mean cost was \$50 among all utilizers and \$97 among those with non-zero cost, a $94.0 \%$ increase. The smallest proportional difference was a $10.2 \%$ increase $(\$ 49$ vs. \$54) for patients with non-zero costs for breast-related outpatient office visits. The largest dollar value increase was $\$ 120$ for MRI (\$187 vs \$307). Among patients with non-zero cost, the mean patient costs were substantially greater than median costs consistently across all utilization types. The larger cost difference between the median and $75^{\text {th }}$ percentile relative to the median and $25^{\text {th }}$ percentile further demonstrated the positive skew among patients with non-zero costs.

The total patient cost associated with utilization after unnecessary recall was influenced by the utilization of services by patients without any cost burden for such services (Table 3 ). The mean (standard deviation) total patient cost among all recalled patients was $\$ 137.98$ (\$303.24), while the mean total among patients with a non-zero cost was $49.8 \%$ greater [\$206.71 (\$351.49)]. Recalled patients requiring a biopsy bore a larger mean total cost $[\$ 448.65$ (\$636.97)]. More than a quarter of the overall and age-stratified populations of recalled patients were not responsible for any direct utilization costs. The mean total patient costs were similar in patients ages 40 to 49 [ $\$ 145.40(\$ 303.24)]$ compared with those ages 50 to 64 [\$134.74 (\$298.99)], but the total cost was less among patients 65 to 75 years of age [\$74.33 (\$162.47)]. Patient costs associated with all-cause outpatient office visits, laboratory services, pharmaceuticals, and mental health office visits were consistent during the 6 months prior to the index screening mammogram compared with the 6 months afterwards. 
Table 4. Number of Days with Recall Associated Utilization in Patients Recalled Unnecessarily after the Index Screening Mammogram by Age Cohort

\begin{tabular}{lcccc}
\hline $\begin{array}{l}\text { Number of days } \\
\text { with a recall procedure }\end{array}$ & $\begin{array}{c}\text { All recalled } \\
\text { patients } \mathrm{N}(\%)\end{array}$ & $\begin{array}{c}\text { Age 40-49 } \\
\mathrm{n}(\%)\end{array}$ & $\begin{array}{c}\text { Age 50-64 } \\
\mathrm{n}(\%)\end{array}$ & $\begin{array}{c}\text { Age 65-75 } \\
\mathrm{n}(\%)\end{array}$ \\
\hline 1 day $^{\mathrm{b}}$ & $259,028(100.0)$ & $128,299(100.0)$ & $121,997(100.0)$ & $8,732(100.0)$ \\
2 days & $55,849(21.6)$ & $25,570(19.9)$ & $27,983(22.9)$ & $2,233(25.6)$ \\
3 days & $17,198(6.6)$ & $6,791(5.3)$ & $9,462(7.8)$ & $892(10.2)$ \\
4 days & $7,466(2.9)$ & $2,707(2.1)$ & $4,288(3.5)$ & $441(5.1)$ \\
5 days & $3,394(1.3)$ & $1,184(0.9)$ & $1,983(1.6)$ & $212(2.4)$ \\
$>5$ days & $2,317(0.9)$ & $852(0.7)$ & $1,337(1.1)$ & $119(1.4)$ \\
\hline
\end{tabular}

${ }^{\mathrm{a}}$ The number of distinct calendar days with a recall-specific procedure.

${ }^{\mathrm{b}}$ All patients had at least 1 day with a recall-associated utilization as defined in the inclusion criteria.

\section{Number of days with recall-associated utilization}

Recall induces further utilization that requires time and may occur on one or more days after the index screening mammogram. Of all recalled patients, $33.3 \%$ had at least two days with recall utilization, $11.7 \%$ had at least three days, and $5.1 \%$ had four or more with recall utilization (Table 4). Fewer women in the youngest cohort (ages 40-49 years) had multiple days with recall utilization (28.9\%) compared with women ages 50-64 (36.9\%) and ages 65-75 (44.6\%). Similarly, only $0.7 \%$ of women in the youngest age cohort had greater than five days with recall utilization, relative to $1.1 \%$ of women ages $50-64$ years and $1.4 \%$ of women ages $65-75$.

\section{Discussion}

The financial burden to patients from health care utilization due to unnecessary recall following a screening mammogram was found to be significant and disproportionately distributed. Although the study population encompassed only women insured through an employer, variability in coverage and utilization of recall-related procedures created substantial disparities in costs borne by the patient. More than onequarter of all recalled patients incurred no utilization costs, in contrast to hundreds of dollars borne among patients with non-zero costs and several hundred dollars among patients with biopsy. This imbalance is evident in the large standard deviations associated with individual procedure and total utilization costs (i.e., a marked number of patients who underwent a biopsy sustained costs in excess of $\$ 1,000$ ). However, computed values of direct utilization costs only partially explain the aggregate burden of recall, as the entirety of the patient burden is reflected through a combination of direct, indirect, and intangible costs. The opportunity cost of time, incurred expenses for travel, and emotional impact of an imminent diagnosis were not borne exclusively by the patients who paid for health care utilization. Rather, these costs are distributed nonuniformly across the entire population of recalled patients.

Costs to patients associated with unnecessary recall have not been extensively reported in the breast cancer screening literature. Analysis of the 2000 National Health Interview Study indicated that the majority of women were not responsible for out of pocket expenses for screening mammograms, specifically $68 \%$ of women aged $40-64$ and $85 \%$ of women over age
$65{ }^{19}$ More recently, the average patient cost for a mammogram was estimated to be \$33 (2007-2008 US\$), constituting $14.1 \%$ of the $\$ 266$ total mammography expense. ${ }^{18}$ This is consistent with the $\$ 40$ average cost we identified among all recalled patients for diagnostic mammography.

A multi-community study in Florida evaluated patient reported direct and indirect costs of screening, diagnosis, and treatment among women who underwent a breast biopsy and were ultimately diagnosed with benign breast disease or breast cancer. ${ }^{14}$ Average patient costs (unadjusted for inflation, $1991 \$$ to $1995 \$$ ) for diagnostic mammogram (\$33) and ultrasound (\$15) were small, with a larger mammography cost (\$82) reported among uninsured women. Patients diagnosed with benign breast disease on average reported spending 9 hours at appointments and, as a result of recall, traveling a total mean distance of 56 miles. ${ }^{14}$

Although the administrative claims database used in this analysis does not contain costs pertaining to travel and time, the number of distinct days with recall utilization conveyed the significant time burden among women. This burden directly translates into reduced productivity among employed women undergoing recall utilization procedures along with those who may provide companion care. Yabroff and colleagues found substantially increased annual time costs associated with medical care in cancer survivors (age 18-64 years, $\$ 500.28$; age $\geq 65$, \$912.96) compared with individuals without a cancer history (age 18-64, \$225.97; age $\geq 65$, $\$ 606.91) .^{25}$ These estimates were obtained using national level time and cost estimates from national survey data (Medical Expenditure Panel Survey, National Ambulatory Medical Care Survey, National Hospital Ambulatory Medical Care Survey, National Health Interview Survey), the Bureau of Labor Statistics median hourly wage rate of $\$ 16.57$, and the hourly value of home production of $\$ 5.32$ per hour. ${ }^{25}$ Use of these values in conjunction with travel and outpatient visit times (travel, urban/rural: 35/39 minutes; visit, urban/rural: 52/53 minutes) would likely estimate greatly increased time costs for recalled patients. A third of the recalled population in our study had multiple days with a recall-related procedure, which may translate into multiple days of costs and opportunity costs for the patient and companion.

Additional relevant costs to patients such as premiums and deductibles were not available for evaluation, but the contribution of such costs to the patient burden should be 
noted. In 2013, the average annual premium contribution among workers with employer sponsored insurance was $\$ 999$ for single coverage, while the average deductible amount for single coverage was $\$ 1,135 .^{26}$ These costs are not insignificant, and have increased markedly over the preceding decade. The transition from patient to health care consumer in the United States is being facilitated by increasing transparency of health care costs and is evidenced by growing enrollment in consumer-directed health plans. ${ }^{26}$ Financial incentives associated with high deductible plans and increased out-of-pocket costs have the potential to influence patient behavior, ${ }^{27}$ potentially manifesting as changes in screening frequency or redirection of volume to high quality providers and services with leading cancer detection rates and lower rates of recall.

The national recall rate in the United States has been estimated to be above recommended performance benchmarks and more than double rates reported in the United Kingdom. $^{28}$ The estimated national cost of screening mammography in 2010 was $\$ 6.2$ billion, with the cost of recall utilization (i.e., imaging and biopsies from true and false positives) responsible for an additional $\$ 1.6$ billion. $^{29}$ The claims-based recall rate of $15 \%$ in the present study exceeds the recommended clinical performance benchmark of $10 \%,{ }^{30}$ and the discrepancy would be even greater if patients with true positive breast cancers had also been included. It follows that a reduction in the burden of recall on the patient and the health care system can be achieved most effectively through a reduction in the proportion of patients recalled.

Multiple approaches to accomplishing the goal of decreasing recall have been proposed and evaluated. Decreasing the frequency of screening and individualizing screening recommendations based upon age and risk (as outlined in the USPSTF guidelines) has been suggested to increase screening coverage while reducing the composite cost of screening and recall. ${ }^{29}$ Alternative interventions have utilized double reading and additional radiologist training with variable success. Breast tomosynthesis is approved by the U.S. Food and Drug Administration and has been demonstrated to reduce recall while increasing cancer detection in large multisite populations of women. ${ }^{31}$ A 13 -site study of academic and nonacademic centers in the United States compared 2-D digital mammography with 3 -D breast tomosynthesis. The recall rate per 1,000 screens was $15 \%$ less for patients screened with tomosynthesis ( 91 per 1,$000 ; 95 \%$ confidence interval [CI] 73-108) compared with digital mammography (107 per 1,000; 95\% CI 89-124). An increased cancer detection rate was also observed with tomosynthesis (5.4 per 1,000;, 95\% CI 4.9-6.0) relative to digital mammography (4.2 per 1,$000 ; 95 \%$ CI $3.8-4.7){ }^{31}$ A prior cost analysis conducted using the Truven Health MarketScan Commercial and Medicare Supplemental Databases modeled health plan cost reductions as a result of reducing recall rates from $13.6 \%$ to less than $10 \%$ (using a $30 \%-40 \%$ range of previously reported recall rate reductions). ${ }^{16,32-36}$ The analysis demonstrated potential savings per patient screened between $\$ 50$ and $\$ 67$, assuming an incremental cost of $\$ 50$ per screening. ${ }^{16}$

Direct and indirect cost savings from reduced recall with breast tomosynthesis would be expected to reduce the patient burden. A relative reduction in the recall rate of similar magnitude to that achieved in the recent tomosynthesis study by Friedewald and colleagues ${ }^{31}$ would result in a larger ab- solute recall reduction in our real-world population but would still fall short of the established $10 \%$ clinical performance standard. However, extrapolations of results from mammography studies are limited by inter-professional variability in mammographic expertise and preferences towards improved cancer detection versus fewer false positives. Further evidence of real-world usage and longer term follow-up is necessary to fully characterize the sensitivity, specificity and the impact on important health outcomes of this new technology.

This study has several limitations. Patients with breast cancer that did not have a diagnosis claim within the 6-month period after the index mammography screening may have been misclassified as unnecessary screening recalls. This potential source of bias is reduced by inclusion of costs from recall utilization, without inclusion of costs of breast cancer treatment, in the measure of patient burden. The use of diagnostic imaging necessary to be identified as recalled in our study most closely approximated BI-RADS definitions of recall; however, in rare circumstances it may have led to an underreporting of recall due to misclassification of patients that were in fact recalled but went directly to MRI, biopsy, or fine needle aspiration without diagnostic imaging. Also, patients undergoing screening ultrasound following a screening mammogram (due to dense tissue) may have been misclassified as recalled unnecessarily, which could have artificially inflated the recall rate.

Additional limitations were present due to the inability of claims data to provide information on indirect costs and intangible costs relating to time, travel, and psychological consequences of recall. The analysis also did not include insurance premiums and could not account for where patients were in regards to meeting their annual deductible or other cost sharing arrangements. This information would have been valuable in further characterizing differences between patients for whom the health plan covered the entire cost of recall utilization, and patients with out- of-pocket costs. Finally, the patients in this study were commercially insured and the results of this study do not reflect costs to uninsured patients or those covered by other insurance programs, such as Medicaid, full Medicare, or Veteran's Affairs. Socioeconomic, ethnic, and racial factors have been shown to influence care patterns following abnormal mammography screening results ${ }^{37}$ but were not assessable in the commercial claims database.

\section{Conclusion}

The patient cost burden associated with recall after a false positive screening mammogram was considerable, approximately \$138 among all recalled women and \$449 among those who underwent a biopsy. More than a quarter of recalled patients were not responsible for any direct costs, contributing to large variability in cost burden as a result of health plan coverage. All patients were subject to the burden of indirect costs and associated time spent in recall. Substantial divergence in cost burden and a recall rate of $15 \%$ was found in this population of women with insurance through an employer. The impact of recall on diverse populations of women requires further investigation and should include characterization of the indirect and intangible costs associated with a false positive screening result. Ultimately, 
the patient burden from unnecessary recall will most effectively be reduced through interventions and technologies intended to decrease the incidence of false positives, therein reducing the recall rate and subsequent costs to patients and the health care system.

\section{Acknowledgments}

The authors gratefully acknowledge the contributions of Valerie Montgomery Rice, Phillip P. Krebs, and Ashok V. Vegesna, who reviewed and provided valuable comments, guidance, and direction in the development of this article.

\section{Disclosure Statement}

Dr. Alcusky, Dr. Skoufalos, and Ms. Clarke are employed by the Jefferson School of Population Health. The school received financial support from Mary Ann Liebert, Inc., Publishers, to review the literature, consult with designated experts, develop, and author this article. Dr. Bonafede is an employee of Truven Health Analytics, which was awarded a research contract by Hologic to conduct this study. Dr. Bonafede did not receive any direct remuneration from Hologic. Dr. Philpotts received an honorarium from Mary Ann Liebert, Inc., publishers for her participation in this article.

\section{References}

1. DeSantis C, Ma J, Bryan L, Jemal A. Breast cancer statistics, 2013. CA Cancer J Clin 2014;64:52-62.

2. Smith RA, Saslow D, Sawyer KA, et al. American Cancer Society guidelines for breast cancer screening: Update 2003. CA Cancer J Clin 2003;53:141-169.

3. American College of Obstetricians-Gynecologists. Practice bulletin no. 122: Breast cancer screening. Obstet Gynecol 2011;118:372-382.

4. U.S. Preventive Services Task Force. Screening for breast cancer: U.S. Preventive Services Task Force recommendation statement. Ann Intern Med 2009;151:716-726, W-236.

5. Gøtzsche PC, Jørgensen KJ. Screening for breast cancer with mammography. Cochrane Database Syst Rev 2013;6: CD001877.

6. Independent UK Panel on Breast Cancer Screening. The benefits and harms of breast cancer screening: An independent review. Lancet 2012;380:1778-1786.

7. Helvie MA, Chang JT, Hendrick RE, Banerjee M. Reduction in late-stage breast cancer incidence in the mammography era: Implications for overdiagnosis of invasive cancer. Cancer. 2014;120:2649-2656.

8. Biller-Andorno N, Jüni P. Abolishing mammography screening programs? A view from the Swiss Medical Board. N Engl J Med 2014;370:1965-1967.

9. Pace LE, He Y, Keating NL. Trends in mammography screening rates after publication of the 2009 US Preventive Services Task Force recommendations. Cancer 2013;119: 2518-2523.

10. Canadian Task Force on Preventive Health Care. Recommendations on screening for breast cancer in averagerisk women aged 40-74 years. CMAJ 2011;183:1991-2001.

11. Forrest APM. Breast cancer screening: Report to the Health Ministers of England, Wales, Scotland and Northern Ireland by a working group. London: HM Stationery Office, 1987.

12. Hubbard RA, Kerlikowske K, Flowers CI, Yankaskas BC, Zhu W, Miglioretti DL. Cumulative probability of false positive recall or biopsy recommendation after 10 years of screening mammography: A cohort study. Ann Intern Med. 2011;155:481-492.

13. Elmore JG, Barton MB, Moceri VM, Polk S, Arena PJ, Fletcher SW. Ten-year risk of false positive screening mammograms and clinical breast examinations. N Engl J Med 1998;338:1089-1096.

14. Secker-Walker RH, Vacek PM, Hooper GJ, Plante DA, Detsky AS. Screening for breast cancer: Time, travel, and outof-pocket expenses. J Natl Cancer Inst 1999;91:702-708.

15. Tosteson AN, Fryback DG, Hammond CS, et al. Consequences of false positive screening mammograms. JAMA Intern Med 2014;174:954-961.

16. Bonafede MM, Miller JD, Lenhart GM, Nelson J, Fajardo LL. Health insurer burden of patient recall following breast cancer screening mammography: Potential impact of 3D mammography. Value Health 2014;17:A82.

17. Madan J, Rawdin A, Stevenson M, Tappenden P. A rapidresponse economic evaluation of the UK NHS Cancer Reform Strategy breast cancer screening program extension via a plausible bounds approach. Value Health 2010;13: 215-221.

18. LeMasters T, Sambamoorthi U. A national study of out-ofpocket expenditures for mammography screening. J Womens Health (Larchmt) 2011;20:1775-1783.

19. Makuc DM, Breen N, Meissner HI, Vernon SW, Cohen A. Financial barriers to mammography: who pays out-ofpocket? J Womens Health (Larchmt) 2007;16:349-360.

20. McAlearney AS, Reeves KW, Tatum C, Paskett ED. Cost as a barrier to screening mammography among underserved women. Ethn Health 2007;12:189-203.

21. Bolejko A, Zackrisson S, Hagell P, Wann-Hansson C. A roller coaster of emotions and sense-coping with the perceived psychosocial consequences of a false positive screening mammography. J Clin Nurs 2014;23:2053-2062.

22. Hafslund B, Nortvedt MW. Mammography screening from the perspective of quality of life: a review of the literature. Scand J Caring Sci 2009;23:539-548.

23. Brodersen J, Siersma VD. Long-term psychosocial consequences of false positive screening mammography. Ann Fam Med 2013;11: 106-115.

24. Woolley C, Philips Z, Whynes DK, et al.; TOMBOLA Group. United Kingdom cervical cancer screening and the costs of time and travel. Int J Technol Assess Health Care 2007;23:232-239.

25. Yabroff KR, Guy GP Jr, Ekwueme DU, et al. Annual patient time costs associated with medical care among cancer survivors in the United States. Med Care 2014;52: 594-601.

26. Claxton G, Rae M, Panchal N, et al.. Health benefits in 2013: Moderate premium increases in employer-sponsored plans. Health Aff (Millwood) 2013;32:1667-1676.

27. Fronstin P. Findings from the 2012 EBRI/MGA Consumer Engagement in Health Care Survey. EBRI Issue Brief 2012;(379):1-27.

28. Smith-Bindman R, Chu PW, Miglioretti DL, et al. Comparison of screening mammography in the United States and the United kingdom. JAMA 2003;290:2129-2137.

29. O'Donoghue C, Eklund M, Ozanne EM, Esserman LJ. Aggregate cost of mammography screening in the United States: comparison of current practice and advocated guidelines. Ann Intern Med 2014;160:145.

30. Rosenberg RD, Yankaskas BC, Abraham LA, et al. Performance benchmarks for screening mammography. 
Radiology 2006;241:55-66. Erratum in: Radiology 2014; 271:620.

31. Friedewald SM, Rafferty EA, Rose SL, et al. Breast cancer screening using tomosynthesis in combination with digital mammography. JAMA 201425;311:2499-2507.

32. Skaane P, Bandos AI, Gullien R, et al. Comparison of digital mammography alone and digital mammography plus tomosynthesis in a population-based screening program. Radiology 2013;267:47-56.

33. Ciatto S, Houssami N, Bernardi D, et al. Integration of $3 \mathrm{D}$ digital mammography with tomosynthesis for population breast-cancer screening (STORM): A prospective comparison study. Lancet Oncol 2013;14583-589.

34. Rose SL, Tidwell AL, Bujnoch LJ, Kushwaha AC, Nordmann AS, Sexton R Jr. Implementation of breast tomosynthesis in a routine screening practice: An observational study. AJR Am J Roentgenol 2013;200:1401-1408.

35. Haas BM, Kalra V, Geisel J, Raghu M, Durand M, Philpotts LE. Comparison of tomosynthesis plus digital mam- mography and digital mammography alone for breast cancer screening. Radiology 2013;269:694-700.

36. Destounis S, Arieno A, Morgan R. Initial experience with combination digital breast tomosynthesis plus full field digital mammography or full field digital mammography alone in the screening environment. J Clin Imaging Sci 2014;4:9.

37. Pérez-Stable EJ, Afable-Munsuz A, Kaplan CP, et al. Factors influencing time to diagnosis after abnormal mammography in diverse women. J Womens Health (Larchmt) 2013;22: 159-166.

Address correspondence to: Alexandria Skoufalos, EdD Jefferson School of Population Health 901 Walnut Street $10^{\text {th }}$ Floor

Philadelphia, PA 19107

E-mail: Alexis.Skoufalos@jefferson.edu 